\title{
Antibacterial Activity of Copper-Loaded Plasma-Treated Natural Zeolites
}

\author{
Arantxa Danielle S. Montallana, Czerr Eljohn V. Cruz, \& Magdaleno R. \\ Vasquez, Jr.* \\ Department of Mining, Metallurgical, and Materials Engineering, College of Engineering, University \\ of the Philippines, Diliman, Quezon City 1101, The Philippines \\ *Address all correspondence to: Magdaleno R. Vasquez, Jr., DMMME Bldg., Velasquez St. cor. C.P. Garcia Ave., UP \\ Diliman, Quezon City 1101, Philippines; Tel.: +63 2981 8500, ext. 3132, E-mail: mrvasquez2@up.edu.ph
}

\begin{abstract}
Copper-exchanged zeolites (CuZ) were prepared through ion exchange at varying concentrations of copper chloride $\left(\mathrm{CuCl}_{2}\right)$ solutions. The samples were tested for their antimicrobial activity against representative microorganisms of Gram-positive Staphylococcus aureus and Gram-negative Escherichia coli. Enhanced ion exchange capacity of natural zeolite was achieved by irradiating sodium-exchanged zeolite (NaZ) with $13.56-\mathrm{MHz}$ radiofrequency argon (Ar) discharged for $20 \mathrm{~min}$ at $25 \mathrm{~W}$ power. We compared the $\mathrm{Cu}$ uptake of pristine and plasma-treated samples soaked in 10, 20, 30, 40, and $50 \mathrm{~mm} \mathrm{CuCl}_{2}$ solutions using energy dispersive-X-ray fluorescence spectroscopy. An increase in $\mathrm{Cu}$ uptake was realized when $\mathrm{NaZ}$ was treated with Ar plasma. The physical effect of plasma treatment was observed under a scanning electron microscope. We found, in particular, that the Ar gas discharge was able to etch through the surface of the zeolite samples, creating more active sites for ion exchange. Mueller-Hinton antimicrobial assays further verified the successful incorporation of $\mathrm{Cu}$ into the zeolite framework by the appearance of inhibition zones in the E. coli and S. aureus cultures, an indication of antimicrobial activity due to the presence of $\mathrm{Cu}$ and its oxides.
\end{abstract}

KEY WORDS: zeolite, ion exchange, antibacterial, plasma treatment

\section{INTRODUCTION}

Metals and metal oxides have been used for their antimicrobial properties for thousands of years. Metallic nanomaterials such as silver $(\mathrm{Ag})$, copper $(\mathrm{Cu})$, and metal oxides possess strong antimicrobial activities. ${ }^{1}$ It has been postulated that the antibacterial property of nanometals arises from their small particle size and high specific surface area. High specific area allows more interaction with microorganisms, and the greater release of metal ions from the particle surface results in increased efficiency of antimicrobial activity. ${ }^{2}$ However, metallic nanoparticles (NPs) also tend to agglomerate, decreasing their surface area and consequently their antimicrobial efficiency. ${ }^{3}$ In addition, metal ions easily oxidize and lose their antimicrobial activity due to the change in their oxidation state from $M^{+}$to $M^{0}{ }^{3}$ To address these limitations, we incorporated nanosized metals and metal oxides with polymer and ceramic matrices such as silica, hydrogel networks, or zeolites. A number of studies have already been conducted studying the antimicrobial properties of heavy metal-loaded zeolite. ${ }^{4,5}$ Because zeolite has more ion exchange properties than other supports, such as silica, alumina, and aluminosilicate, this prevents oxidation of loaded metals and enables uniform distribution on the surface. ${ }^{6}$ 
Zeolites are naturally occurring, crystalline tecto-aluminosilicates comprised of $\mathrm{TO}_{4}$ tetrahedra $(T=$ tetrahedral species $\mathrm{Si}, \mathrm{Al}$, $\mathrm{P}$, etc. $){ }^{7}$ Three-dimensional structures consisting of $\left(\mathrm{AlO}_{4}\right)^{5-}$ and $\left(\mathrm{SiO}_{4}\right)^{4-}$ share their oxygen atoms. Clinoptilolite, one of the common natural structures of zeolite, is known for its efficient ion exchange capabilities due to its cage-like structure that tends to encapsulate exchanged metals in its lattice. ${ }^{8,9}$ This property of zeolites makes them suitable for industrial applications such as heavy metal adsorption in wastewater treatment. Due to their nontoxicity and biocompatibility, their applications in bone tissue engineering and in the biomedical field have also been widely studied; it has been reported that zeolites may be used for bioactivity and in vitro compatibility in bone tissue engineering applications. ${ }^{6}$

A significant number of studies have suggested that areas of application could be expanded through functionalization of the zeolite surface. ${ }^{10}$ One method of surface modification is via the use of gas discharges, also known as plasma. Radio-frequency (RF) plasma discharge is produced when oscillations of an applied field cause excitation, dissociation, and ionization of gas molecules as they collide with electrons. ${ }^{11} \mathrm{RF}$ plasma can be generated at a power source frequency of $13.56 \mathrm{MHz} .{ }^{12}$ The use of plasma for surface modification is one of the most economical methods and, unlike wet processes, does not usually produce toxic by-products. ${ }^{13}$ Plasma-surface interactions result in changes in surface free energy, ${ }^{14}$ sterilization, ${ }^{15}$ and residue removal. ${ }^{11}$ In biomedical applications, exposure of chitosan to $\mathrm{Ar}-\mathrm{N}_{2}-\mathrm{H}_{2}$ plasma is reported to contribute to increases in amine functional group, which results in improved blood clotting and drug delivery. ${ }^{16}$ In addition, a study by Taaca and Vasquez confirmed hemocompatibility and cytocompatibility of silver-zeolite-chitosan composites. ${ }^{17}$ These authors used plasma to tailor surface properties without affecting the bulk properties of the composites.

In this study, the effect of RF plasma on the $\mathrm{Cu}$ ion exchange capacity of zeolite was explored, particularly aiming to increase $\mathrm{Cu}$ uptake in the zeolite framework through plasma treatment, hence increasing the amount of $\mathrm{Cu}$ available for interaction with pathogens and increasing the release of metal ions from the particle surface, which could result in increased efficiency of antimicrobial activity.

\section{EXPERIMENTALPROCEDURE}

\section{A. Preparation of Natural Zeolite}

Natural zeolite samples containing $68.6 \%$ clinoptilolite (with quartz and hematite as the major impurities) were collected from an open pit mine of SAILE Industries (Mangatarem, Pangasinan, Philippines). The as-received tuffaceous zeolite material was subsequently washed four times with deionized water $\left(\mathrm{DI} \mathrm{H}_{2} \mathrm{O}\right.$ ), soaked in $3 \mathrm{~m}$ hydrochloric acid $(\mathrm{HCl})$ solution for $12 \mathrm{hr}$, and washed again with $\mathrm{DI}_{2} \mathrm{O}$ to eliminate impurities and loosely bound ions present on the surface. The samples were then filtered and ovendried for $3 \mathrm{hr}$ at $150^{\circ} \mathrm{C} .{ }^{18-20}$ To increase the clinoptilolite cation exchange capacity of the material, the acid-washed zeolites were impregnated with sodium ions $\left(\mathrm{Na}^{+}\right)$by soaking the powder in $4 \mathrm{~m}$ sodium chloride $(\mathrm{NaCl})$ solution for $24 \mathrm{hr}$. The sodium-exchanged 
zeolites (NaZ) were filtered, washed, and dried. The tuffaceous zeolite material was ground for extended periods to obtain finer powders.

\section{B. Plasma Treatment}

One gram of the $\mathrm{NaZ}$ powder was weighed and evenly distributed onto a Petri dish. The powders were irradiated with 13.56-MHz RF plasma at $25 \mathrm{~W}$ using argon (Ar) gas for $20 \mathrm{~min}$. The plasma system consisted of a bell jar terminated by a flange. Details of the RF plasma system are described elsewhere by Cagomoc and Vasquez. ${ }^{20}$

\section{C. lon Exchange}

We diluted $100 \mathrm{~mm}$ copper chloride $\left(\mathrm{CuCl}_{2}\right)$ stock solution to 50, 40, 30, 20, and $10 \mathrm{~mm}$ to produce $20-\mathrm{mL} \mathrm{CuCl}_{2}$ solutions. We soaked $5 \mathrm{~g}$ of the untreated and plasma-treated $\mathrm{NaZ}$ powders in each $\mathrm{Cu}$ concentration for $24 \mathrm{hr}$, filtered, and oven-dried at $150^{\circ} \mathrm{C}$.

\section{Characterization}

The copper-exchanged zeolite $(\mathrm{CuZ})$ samples were prepared for characterization by weighing $0.30 \mathrm{~g} \mathrm{CuZ}$ powders and pelletizing at 3000 pound force per square inch, with 3 min holding time, using a hydraulic press. We examined the incorporation of $\mathrm{Cu}$ into the zeolite framework using energy dispersive-X-ray fluorescence (ED-XRF) spectroscopy. The phases of $\mathrm{Cu}$ present in the zeolite framework were determined through X-ray diffraction (XRD). A scanning electron microscope (SEM) was also used to determine the effect of plasma treatment on the surface of the zeolite. The untreated and plasmatreated $\mathrm{NaZ}$ and $\mathrm{CuZ}$ samples were subjected to the Mueller-Hinton antimicrobial assay (MHAA) in triplicate to determine the inhibitory effect of the samples on Escherichia coli and Staphylococcus aureus growth. The suspending medium containing $0.1 \%$ peptone water and the pathogens were swabbed several times on the MH agar plate and incubated for $24 \mathrm{hr}$ at $35^{\circ} \mathrm{C}$. The zones of inhibition of microbial growth were measured in millimeters. The antimicrobial index (AI) was calculated using the following equation:

$$
\mathbf{A I}=\frac{\text { Diameter of Clearing Zone-Diameter of Pellet }}{\text { Diameter of Pellet }}
$$

\section{RESULTS AND DISC USSION}

\section{A. ED-XRF Spectroscopy}

$\mathrm{Cu}$ was successfully incorporated into the zeolite framework, as shown in Fig. 1. We achieved increased uptake of $\mathrm{Cu}$ in the zeolite by soaking the zeolites in higher $\mathrm{CuCl}_{2}$ concentrations. Increased uptake can also be realized by pretreating zeolites using $\mathrm{Ar}$ 


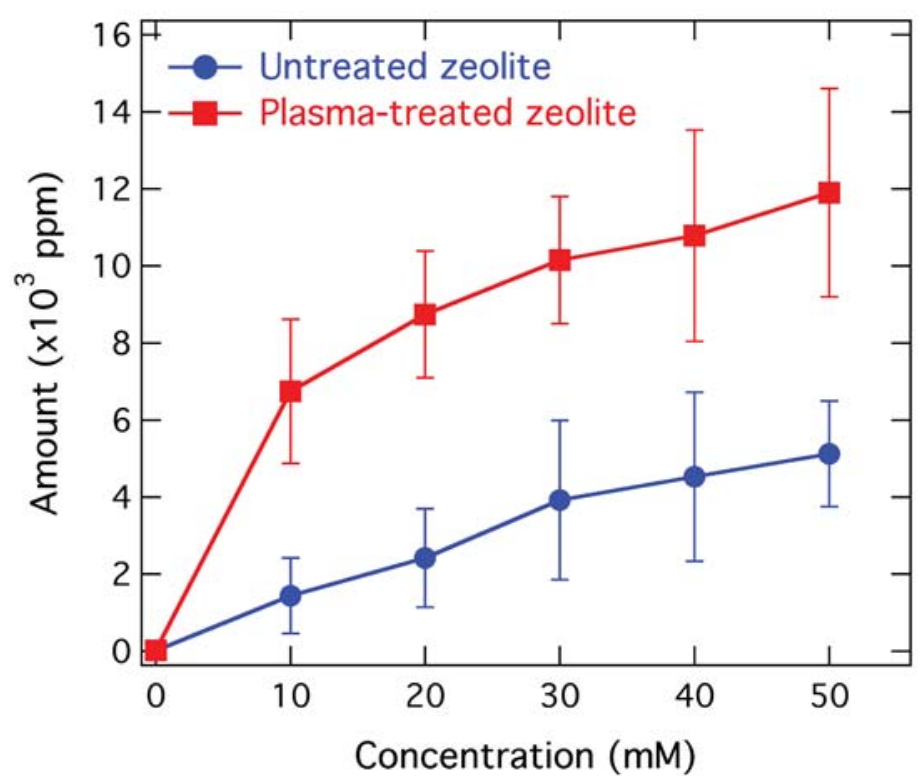

FIG. 1: $\mathrm{Cu}$ uptake of untreated and plasma-treated $\mathrm{CuZ}$ versus $\mathrm{CuCl}_{2}$ precursor concentration. ppm, Parts per million.

$\mathrm{RF}$ plasma. $\mathrm{Cu}^{2+}$, having a much smaller radius, can easily enter the channels of clinoptilolite; hence, it can readily exchange with $\mathrm{Na}^{+} .{ }^{21}$ The concentration gradient of ions between the solid and liquid phases is also a driving force for ion exchange. ${ }^{22}$

\section{B. Statistical Analysis}

A two-way analysis of variance (ANOVA) was performed to test the significance of plasma treatment and the increasing concentration of the precursor solution. A probability value of 0.05 was used to compare with the calculated $p$ values. The obtained $p$ values (Table 1) for plasma treatment and the precursor concentration factor were both

TABLE 1: ANOVA for Cu uptake of untreated and plasma-treated samples

\begin{tabular}{lcccccc}
\hline $\begin{array}{l}\text { Source of } \\
\text { variation }\end{array}$ & SS & df & MS & $\mathbf{F}$ & $\mathbf{p ~ V a l u e}$ & $\mathbf{F}_{\text {crit }}$ \\
\hline UTR/PTR & $2.387 \mathrm{E} 08$ & 1 & $2.387 \mathrm{E} 08$ & 76.834 & $6.03281 \mathrm{E}-09$ & 4.259677273 \\
Concentration & $2.889 \mathrm{E} 08$ & 5 & $5.777 \mathrm{E} 07$ & 18.592 & $1.47501 \mathrm{E}-07$ & 2.620654148 \\
Interaction & $4.935 \mathrm{E} 07$ & 5 & $9.869 \mathrm{E} 06$ & 3.176 & 0.02433091 & 2.620654148 \\
Within & $7.457 \mathrm{E} 07$ & 24 & $3.107 \mathrm{E} 06$ & & & \\
Total & $6.515 \mathrm{E} 08$ & 35 & & & & \\
\hline
\end{tabular}

ANOVA, one-way analysis of variance; df, degrees of freedom; F, F statistic; $F_{\text {crif }}$, F critical; MS, mean square; PTR, plasma treated; SS, sum of square; UTR, untreated. 
$<0.05$, which implies that the two parameters had a significant effect on the increase of $\mathrm{Cu}$ uptake in zeolite. The interaction between the two factors had a $p$ value of 0.024331 , signifying that there is an interaction between the two factors, plasma treatment, and the concentration of the precursor solution in increasing the $\mathrm{Cu}$ uptake of zeolite, which translates to an increase in its ion exchange capacity.

\section{MHAA}

$\mathrm{CuZ}$ samples exhibited antimicrobial activity after $24 \mathrm{hr}$ of MHAA characterization (Fig. 2). We quantitatively determined the zones of microbial growth inhibition by measuring the diameter of clearing zones at different $\mathrm{CuCl}_{2}$ solution concentrations. The corresponding AIs were calculated using Eq. (1), and Table 2 shows the AI for each sample. The antimicrobial activity of $\mathrm{CuZ}$ against $E$. coli started at $20 \mathrm{~mm}$ for untreated $\mathrm{NaZ}$ and at $10 \mathrm{~mm}$ for plasma-treated NaZ. S. aureus growth inhibition zones, on the other hand, manifested at $10 \mathrm{~mm}$ for both untreated and plasma-treated NaZ.

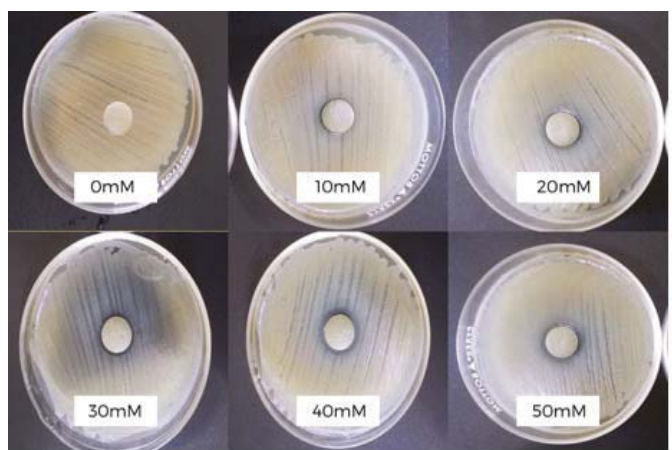

(a)

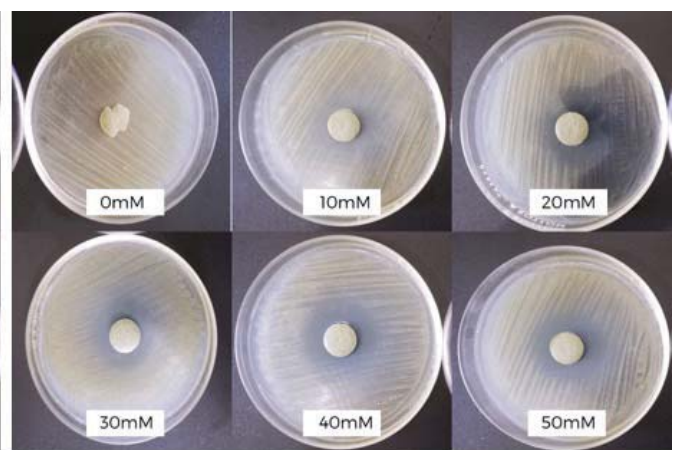

(b)

FIG. 2: Images of the MHAA of CuZ on (a) E. coli and (b) S. aureus cultures

TABLE 2: Computed AIs of CuZ against E. coli and S. aureus

\begin{tabular}{lcccc}
\hline \multirow{2}{*}{$\begin{array}{l}\mathrm{CuCl}_{2} \text { Concentration } \\
(\mathbf{m M})\end{array}$} & \multicolumn{2}{c}{ Untreated } & \multicolumn{2}{c}{ Plasma-treated } \\
\cline { 2 - 5 } & $\boldsymbol{E}$ coli & S. aureus & E. coli & S. aureus \\
\hline 0 & 0.00 & 0.00 & 0.00 & 0.00 \\
10 & 0.00 & 0.15 & 0.05 & 0.15 \\
20 & 0.05 & 0.45 & 0.50 & 0.55 \\
30 & 0.35 & 0.60 & 0.40 & 0.50 \\
40 & 0.30 & 0.60 & 0.40 & 0.60 \\
50 & 0.35 & 0.65 & 0.55 & 0.70 \\
\hline
\end{tabular}

$\mathrm{AI}$, antimicrobial index.

Volume 8, Issue 1, 2018 
At increasing $\mathrm{CuCl}_{2}$ concentrations, we expected an increase in the AIs due to higher concentration of $\mathrm{Cu}$. However, experimental results showed only a slight increase in AIs for pretreated zeolites. This may be due to the limitation of the characterization technique used. The effectiveness of $\mathrm{Cu}, \mathrm{CuO}$, and $\mathrm{Cu}_{2} \mathrm{O}$ against pathogens using a disk

diffusion assay is by surface contact. Hence, the $\mathrm{Cu}, \mathrm{CuO}$, and $\mathrm{Cu}_{2} \mathrm{O}$ that were confined inside the zeolite framework were not used to inhibit bacterial growth in the MHAA.

Plasma-treated samples exhibited higher AIs than pristine samples. This could be attributed to greater $\mathrm{Cu}$ uptake of the plasma-treated zeolites. However, we also observed that increased amounts of $\mathrm{CuO}$ and $\mathrm{Cu}_{2} \mathrm{O}$ in the framework, due to increased concentration of the precursor solution, did not readily translate to an increasing trend in the antimicrobial activity of $\mathrm{CuZ}$. Aside from the limitation of the characterization technique used, the antimicrobial efficiency of metal NPs also depends on size. $\mathrm{CuO}$ NPs tend to agglomerate, hence reducing the surface area and consequently decreasing the area of contact when subjected to bacteria culture. ${ }^{6}$ Although the use of zeolite as support overcame the issue of agglomeration, the present study did not confirm that the metals loaded into the zeolite framework were in nanometer dimensions. The authors suggest a more thorough investigation to confirm the particle size of $\mathrm{Cu}$ present in the framework and relate it to the trend in the antimicrobial activity of CuZ. This can be done through Brunauer-Emmett-Teller measurements and by calculating particle size using the Debye-Scherrer equation from XRD.

\section{SEM}

The surface morphologies of untreated and plasma-treated (Ar, for 20 min at $25 \mathrm{~W}$ ) $\mathrm{NaZ}$ were examined under SEM at 500x and 5000x magnification, as shown in Fig. 3. Samples irradiated with Ar plasma for 20 min at $25 \mathrm{~W}$ power input [Figs. 3(b) and (d)] had noticeable increases in surface roughness when compared to untreated samples [Figs. 3(a) and (c)]. This phenomenon could be attributed to etching of the surface by highly energetic Ar ions impinging the surface. Increases in the surface area create more active sites for ion exchange, enabling the material to accommodate more $\mathrm{Cu}$ ions into its framework..$^{20}$

\section{E. XRD}

An X-ray diffractogram of raw zeolite is shown in Fig. 4. The peak analyzer and percentage of composition of natural zeolite were performed using Match! software (Crystal Impact, Germany). The diffractogram of the raw natural zeolite sample indicated clinoptilolite to be major component at $68.6 \%$, with quartz and hematite as impurities. $\mathrm{CuZ}$ samples were also analyzed using Match!, as seen in Fig. 5. The most pronounced traces of $\mathrm{Cu}$ peaks found in the structure were $\mathrm{CuO}$ and $\mathrm{Cu}_{2} \mathrm{O}$ in the range of $2 \theta=35^{\circ}$ to $39^{\circ}$ for $\mathrm{CuO}$ and $44^{\circ}$ for $\mathrm{Cu}_{2} \mathrm{O}$. Copper oxides were the first peaks to be referenced in the diffractogram of $\mathrm{CuZ}$ because they occurred at ambient conditions $(\mathrm{Cu}$ tends to oxidize). ${ }^{23}$ Even for oxidized $\mathrm{Cu}$, we still found a degree of antimicrobial activity from 

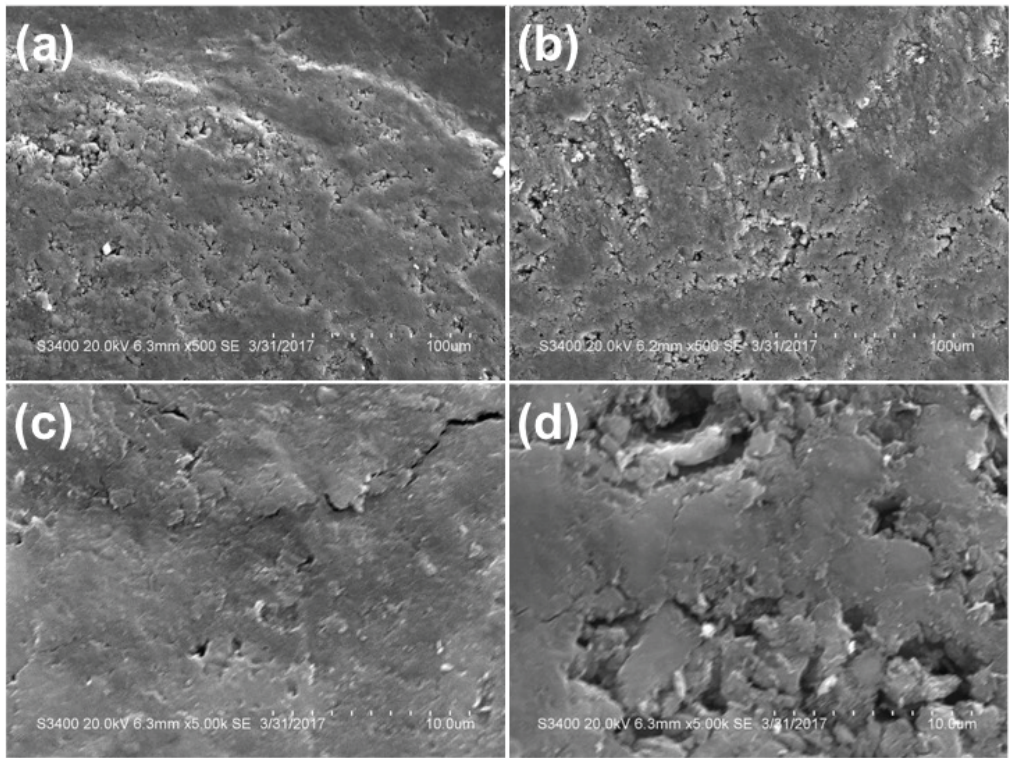

FIG. 3: SEM images of (a) untreated $\mathrm{NaZ}$ at 500×, (b) plasma-treated $\mathrm{NaZ}$ at $500 \times$, (c) untreated $\mathrm{NaZ}$ at $5000 \times$, and (d) plasma-treated $\mathrm{NaZ}$ at $5000 \times$

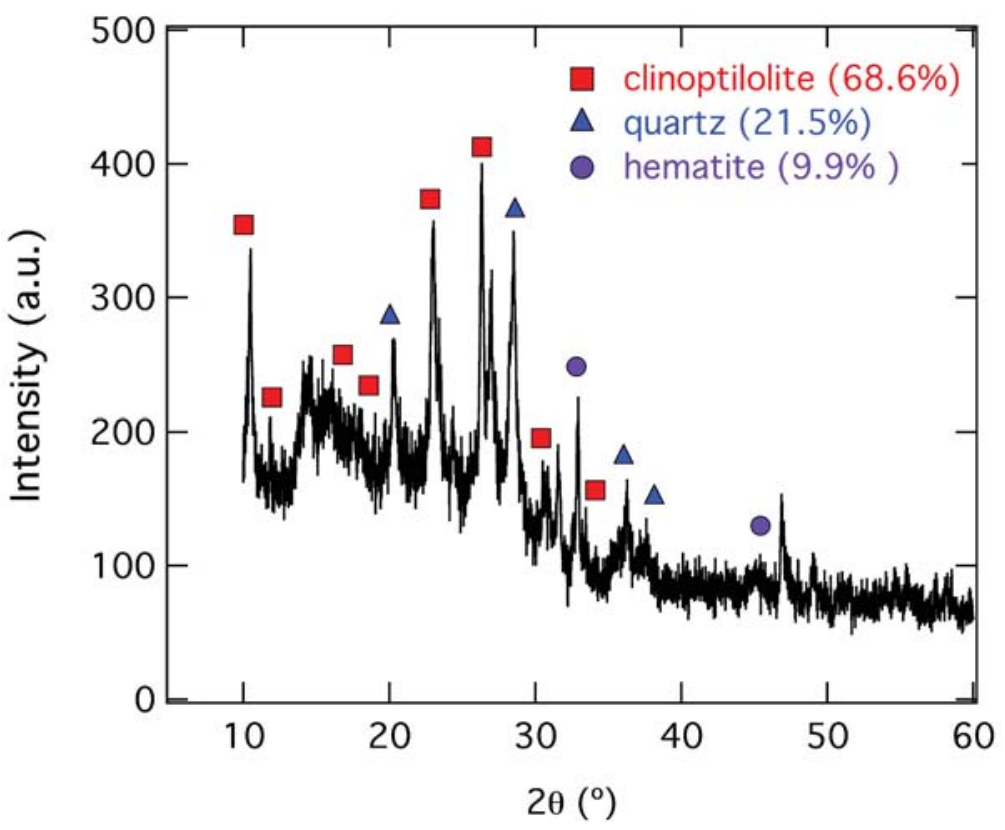

FIG. 4: X-ray diffractogram of the raw zeolite sample 


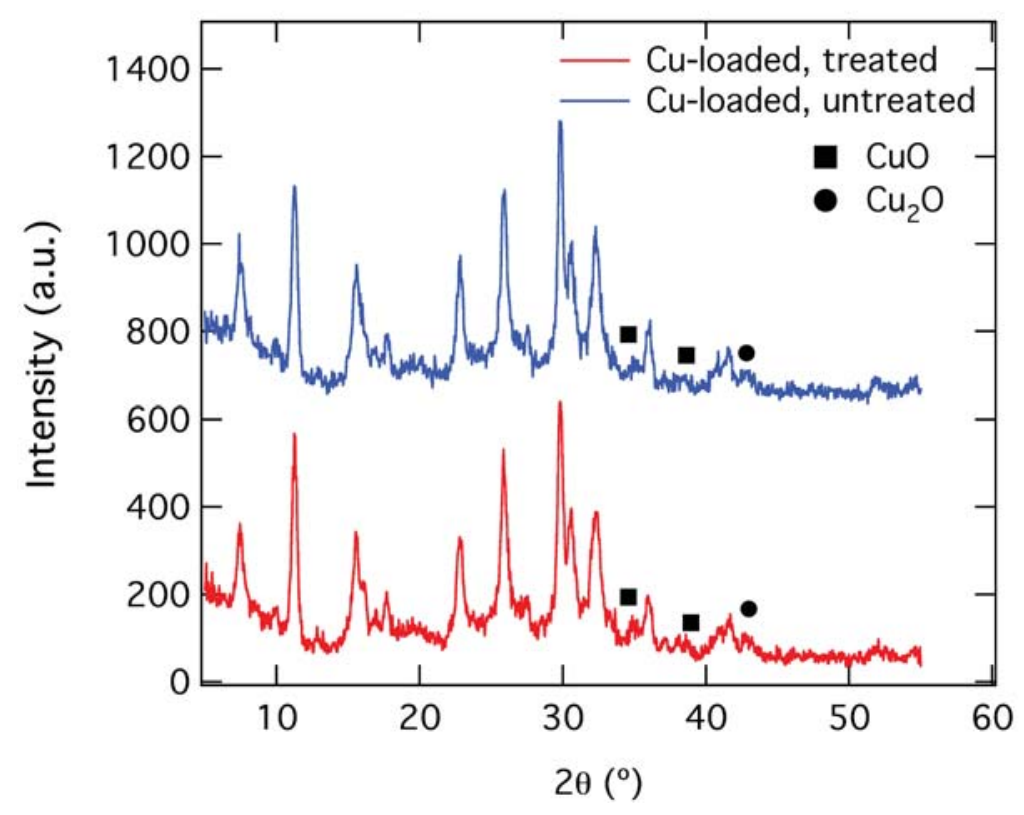

FIG. 5: X-ray diffractogram of $\mathrm{Cu}$-loaded zeolite with and without plasma pretreatment

the structures. ${ }^{24}$ Other phases of $\mathrm{Cu}$ may have been present on the zeolite framework, but due to the background noise of the diffractogram, the intensity of peaks was too small to draw conclusions. Furthermore, background cancellation and curve smoothing must be performed to accurately determine the $\mathrm{Cu}$ phases present in the network.

\section{CONCLUSION}

Increased efficiency in the antibacterial activity of $\mathrm{CuZ}$ against $E$. coli and $S$. aureus was achieved through enhancing the ion exchange capacity of natural zeolites. CuZ exhibited larger inhibition zones and higher AIs against $S$. aureus culture. XRF results confirmed the successful incorporation of $\mathrm{Cu}$ into the zeolite framework, and an increase in $\mathrm{Cu}$ uptake was realized after pretreating the zeolite with Ar plasma. Enhanced $\mathrm{Cu}$ uptake could be attributed to the creation of more active sites after plasma treatment through the roughening of zeolite surface, as revealed in the SEM images. We have shown that plasma treatment is a viable method for zeolite surface functionalization. It is safe, environmentally friendly, and inexpensive.

\section{ACKNOWFDGMENIS}

M.R.V. is grateful to the University of the Philippines Office of the Vice President for Academic Affairs Balik-PhD Research Grant OVPAA-BPhD-2014-01. The authors thank SAILE Industries for providing the natural zeolite samples. 


\section{REFERENCES}

1. Chudobova D, Dostalova S, Ruttkay-Nedecky B, Guran R, Rodrigo MA, Tmejova K, Krizkova S, Zitka O, Adam V, Kizek R. The effect of metal ions on Staphylococcus aureus revealed by biochemical and mass spectrometric analyses. Microbiol Res. 2015;170:147-56.

2. Grumezescu A. Surface chemistry of nanobiomaterials: Applications of nanobiomaterials. Oxford: William Andrew; 2016.

3. Alswat AA, Ahmad MB, Hussein MZ, Ibrahim NA, Saleh TA. Copper oxide nanoparticle-loaded zeolite and its characteristics and antibacterial activities. J Mater Sci Technol. 2017;33:889-96.

4. Hrenovic J, Milenkovic J, Ivankovic T, Rajic N. Antibacterial activity of heavy metal-loaded natural zeolite. J Haz Mater. 2012;201-202:260-4.

5. Demirci S, Ustaoğlu Z, Yılmazer GA, Fikrettin Sahin F, Baç N. Antimicrobial properties of zeolite-X and zeolite-A ion-exchanged with silver, copper, and zinc against a broad range of microorganisms. Appl Biochem Biotechnol. 2014;172:1652-62.

6. Alswat AA, Ahmad MB, Saleh T. Preparation and characterization of zeolite/zinc oxide-copper oxide nanocomposite: Antibacterial activities. Colloid Interface Sci Commun. 2017;16:19-24.

7. Kaučič V. The structure of zeolite and aluminophosphate molecular sieves. Croatica Chemica Acta. 1994;67:241-61.

8. Tekin R, Nurcan B. Antimicrobial behavior of ion-exchanged zeolite X containing fragrance. Micropor Mesopor Mater. 2017;234:55-60.

9. Lee KX, Valla JA. Investigation of metal-exchanged mesoporous Y zeolites for the adsorptive desulfurization of liquid fuels. Appl Catal B Environ. 2017;201:359-69.

10. Apreutesei RE, Catrinescu C, Teodosiu C. Surfactant-modified natural zeolites for environmental applications in water purification. Environ Eng Manage J. 2008;7:149-61.

11. Kohli R, Mittal KL, Developments in surface contamination and cleaning contaminant removal and monitoring. 1st ed. Waltham, MA: William Andrew; 2013.

12. Pierson HO. Handbook of chemical vapor deposition principles, technology and applications. 2nd ed. New York: William Andrew; 1999.

13. Liston EM, Martinu L, Wertheimer MR. Plasma surface modification of polymers for improved adhesion: A critical review. In: Strobel M, Lyons CS, Mittal KL, editors. Plasma surface modification of polymers: Relevance to adhesion. Utrecht: VSP; 1994. p. 3-42.

14. Gomathi N, Neogi S. Surface modification of polypropylene using argon plasma: Statistical optimization of the process variables. Appl Surf Sci. 2009;255:7590-600.

15. Daseco JA, Pabelina KG, Siringan MAT, Ramos HJ. Comparative study on the use of different metal electrodes in low-pressure glow discharge plasma sterilization. Plasma Med. 2014;4:1-10.

16. Zhang HY, Cleymand F, Noël C, Kahn CJF, Linder M, Dahoun A, Henrion G, Arab-Tehrany E. Effects of $\mathrm{Ar}-\mathrm{H}_{2}-\mathrm{N}_{2}$ microwave plasma on chitosan and its nanoliposomes blend thin films designed for tissue engineering applications. Carbohydr Polym. 2013;93:401-11.

17. Taaca KLM, Vasquez MR. Fabrication of Ag-exchanged zeolite/chitosan composites and effects of plasma treatment. Micropor Mesopor Mater. 2017;241:383-91.

18. Wang S, Peng Y. Natural zeolites as effective adsorbents in water and wastewater treatment. Chem Eng J. 2010;156:11-24.

19. Roz ME, Lakiss L, Valtchev V, Mintova S, Thibault-Starzyk F. Cold plasma as environmentally benign approach for activation of zeolite nanocrystals. Micropor Mesopor Mater. 2012;158:148-54.

20. Cagomoc CMD, Vasquez MR. Enhanced chromium adsorption capacity via plasma modification of natural zeolites. Jpn J Appl Phys. 2017;56(1S):01AF02.

21. Ming DW, Dixon JB. Quantitative determination of clinoptilolite in soils by a cation-exchange capacity method. Clays Clay Miner. 1987;35:463-68.

22. Inglezakis VJ. The concept of "capacity" in zeolite ion-exchange systems. J Colloid Interface Sci. 2005;281:68-79.

Volume 8, Issue 1, 2018 
23. Palomino GT, Bordiga S, Zecchina A. XRD, XAS, and IR characterization of copper-exchanged Y zeolite. J Phys Chem B. 2000;104:8641-51.

24. Ren G, Hu D, Cheng EW, Vargas-Reus MA, Reip P, Allaker RP. Characterisation of copper oxide nanoparticles for antimicrobial applications. Int J Antimicrob Agents. 2009;33(6):587-90. 